\title{
Erratum to: Prognostic impact of location and extent of vessel-related ischemia at myocardial perfusion scintigraphy in patients with or at risk for coronary artery disease
}

\author{
Francesco Nudi, $M D,{ }^{\text {a,b }}$ Orazio Schillaci, $M D,{ }^{c}$ Giandomenico Neri, $M D,{ }^{a}$ \\ Annamaria Pinto, MD, , ${ }^{\mathrm{a} d \mathrm{~d}}$ Enrica Procaccini, $\mathrm{MD},{ }^{\mathrm{a}, \mathrm{d}}$ Maurizio Vetere, $\mathrm{BSc}{ }^{\mathrm{a}}$ \\ Giacomo Frati, $M D,{ }^{e, g}$ Fabrizio Tomai, $M D$, ${ }^{f}$ and Giuseppe Biondi-Zoccai, $M D^{e, g}$ \\ a Service of Nuclear Cardiology, Madonna della Fiducia Clinic, Rome, Italy \\ b ETISAN, Rome, Italy \\ c Institute of Nuclear Medicine, Tor Vergata University, Rome, Italy \\ d Ostia Radiologica, Rome, Italy \\ e Department of Medico-Surgical Sciences and Biotechnologies, Sapienza University of Rome, \\ Latina, Italy \\ f Division of Cardiology, European Hospital, Rome, Italy \\ g Department of AngioCardioNeurology, IRCCS Neuromed, Pozzilli, Italy
}

\section{ERRATUM TO: J NUCL CARDIOL 23(2):274-284. DOI 10.1007/S12350-015-0077-8}

Two of the authors, Giacomo Frati and Giuseppe Biondi-Zoccai, have a second affiliation that did not appear in the article published in J Nucl Cardiol. 2016 Apr;23(2):274-284.

The additional affilation is Department of AngioCardioNeurology, IRCCS Neuromed, Pozzilli, Italy, as shown in this erratum.

The online version of the original article can be found under doi: 10.1007/s12350-015-0077-8.

Reprint requests: Francesco Nudi, MD, Service of Nuclear Cardiology, Madonna della Fiducia Clinic, Via Cesare Correnti 6, 00179 Rome,

Italy; francesco.nudi@gmail.com

J Nucl Cardiol 2017;24:1102.

$1071-3581 / \$ 34.00$

Copyright (C) 2017 American Society of Nuclear Cardiology.

doi:10.1007/s12350-017-0849-4 